Jurnal Konstruksi Hukum | ISSN: XXXX | E-ISSN: XXXX Vol. 1, No. 1, September 2020 Hal. 125-129| Available online at https://www.ejournal.warmadewa.ac.id/index.php/jukonhum

DOI: https://doi.org/10.22225/jkh.1.1.2144.125-129

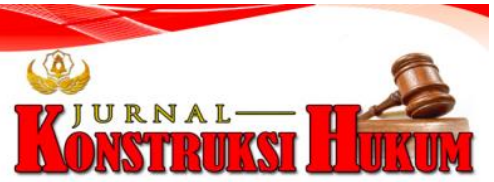

\title{
IMPLEMENTASI UNDANG-UNDANG NOMOR 24 TAHUN 2011 TENTANG BADAN PENYELENGGARAAN JAMINAN SOSIAL PADA PT. HORIKO ABADI KABUPATEN BULELENG
}

\author{
Gede Oscar Geovani, I Nyoman Putu Budiartha, Putu Ayu Sriasih Wesna \\ Fakultas Hukum Universitas Warmadewa, Denpasar-Bali, Indonesia
}

\begin{abstract}
Abstrak
Jaminan sosial memberikan perlindungan bagi tenaga kerja dalam resiko sosial ekonomi yang menimpa tenaga kerja dalam melakukan pekerjaannya baik berupa kecelakaan kerja, sakit, hari tua, maupun meninggal dunia. Dalam skripsi ini dibahas implementasi Undang-Undang Nomor 24 tahun 2011 tentang Badan Penyelenggaraan Jaminan Sosial pada PT. Horiko Abadi Kabupaten Buleleng. Berdasarkan uraian di atas, penelitian ini bertujuan untuk mengetahui penerapan Undang-Undang Nomor 24 Tahun 2011 tentang Badan Penyelenggaraan Jaminan Sosial pada PT. Horiko Abadi Kabupaten Buleleng 2 sanksi hukum terhadap perusahaan dalam hal terjadi pelanggaran terhadap ketentuan dari program jaminan sosial. Metode penelitian yang digunakan yaitu metode yuridis empiris, Lokasi penelitian ini dilakukan pada PT. Horiko Abadi Kabupaten Buleleng perusahaan yang bergerak pada bidang penangkaran kerang dan budi daya mutiara. Berdasarkan hasil penelitian, PT. Horiko Abadi telah menerapkan perlindungan jaminan sosial terhadap seluruh pegawai tetap yang ada di perusahaan tersebut sesuai dengan ketentuan Undang-Undang Nomor 24 Tahun 2011 Tentang Badan Penyelenggaraan Jaminan Sosial, dan sanksi bagi perusahaan yang belum melaksanakan ketentuan undang-undang Undang-Undang Nomor 24 Tahun 2011 Tentang Badan Penyelenggaraan Jaminan Sosial masih dalam tahap pembinaan atau peringatan sampai perusahaan yang bersangkutan bisa menjalankan ketentuan dari Perundang-undangan.
\end{abstract}

Kata Kunci: Jaminan social; Ketenagakerjaan; Sanksi hukum

\begin{abstract}
Social security provides protection for workers in the socio-economic risks that befall workers in carrying out their work in the form of work accidents, illness, old age, or death. This thesis discusses the implementation of Law Number 24 of 2011 concerning the Social Security Administration at PT. Horiko Abadi, Buleleng Regency. Based on the description above, this study aims to determine the application of Law Number 24 of 2011 concerning the Social Security Administration at PT. Horiko Abadi, Buleleng Regency 2 legal sanctions against the company in the event of a violation of the provisions of the social security program. The research method used is the empirical juridical method. The location of this research was conducted at PT. Horiko Abadi, Buleleng Regency, a company engaged in the breeding of shellfish and pearl cultivation. Based on the research results, PT. Horiko Abadi has implemented social security protection for all permanent employees in the company in accordance with the provisions of Law Number 24 of 2011 concerning Social Security Administering Bodies, and sanctions for companies that have not implemented the provisions of Law Number 24 of 2011 Regarding the Social Security Administering Body, it is still in the guidance or warning stage until the company concerned can carry out the provisions of the legislation.
\end{abstract}

Keywords: Social security; Employment; Legal sanctions

\section{PENDAHULUAN}

Pembangunan bangsa memerlukan asset pokok yang disebut sumber daya (resources) baik sumber daya alam (natural resources). Kedua sumber daya tersebut sangat penting dalam menentukan keberhasilan suatu pembangunan. Prospek pembangunan Negara Indonesia untuk mencapai tujuan masyarakat adil dan makmur, dalam arti arah pembangunan yang dilaksanakan ditujukan untuk terciptanya keseimbangan antara pembangunan material dan spiritual. Dengan arah pembangunan tersebut, pemerintah dalam mengembangkan ekonomi, dunia usaha, dan industri membuat perencanaan pembangunan yang tidak hanya memandang dari segi fisik, tetapi juga dari segi pengembangan sumber daya manusianya (Ansori, 2015). Dalam hubungannya dengan masalah 
ketenagakerjaan penjabaran dari ketentuan Pasal 28D Undang-Undang Dasar 1945 di tuangkan dalam bentuk upaya-upaya perluasan lapangan kerja, perlindungan upah, serta pemberian jaminan sosial bagi tenaga kerja itu sendiri. Perlindungan upah bagi tenaga kerja yang sesuai dengan Pasal 28D Undang-Undang Dasar 1945 ini, adalah memberikan sumber pendapatan yang dapat menjamin terpenuhinya kebutuhan akan dasarnya sebagai manusia (human basic need) yang meliputi kebutuhan akan sandang, pangan, perumahan dan pelayanan kesehatan serta lainnya (Sagir, 1998).

Pada dasarnya pandangan mengenai upah dilihat dari sudut majikan (pengusaha) dengan buruh (tenaga kerja) terdapat suatu hal yang bertolak belakang yaitu : "upah dilihat dari unsur majikan adalah unsur dari harga pokok (biaya) dan sebaliknya bila dilihat buruh yaitu merupakan penghasilan" (Manulang, 2001). Peranan tenaga kerja untuk pembangunan bangsa Indonesia terus adanya peningkatan dengan disertai banyaknya hambatan dan tantangan yang dihadapinya. Sebab itu untuk tenaga kerja sendiri perlu diberikan perlindungan, pemeliharaan, dan peningkatan kesejahteraannya agar dapat meningkatkan produktivitas nasional (Maria, 2012). Pembangunan nasional yang terus berlangsung selama ini telah memberikan peluang kerja dan memberikan penghasilan guna pemenuhan standardisasi kehidupan untuk tenaga kerja dan keluarganya. Akan tetapi daya kerja dan penghasilan tersebut dapat berkurang atau hilang karena adanya resiko yang dialami oleh tenaga kerja yaitu sakit, kecelakaan saat melaksanakan pekerjaannya yang akibatnya tidak bisa bekerja sementara, cacat sebagian untuk selama-lamanya, baik fisik maupun mental, dan meninggal dunia (Arfiah \& Setiadi, 2012).

Keikutsertaan pekerja/buruh dalam pembangunan nasional terus meningkat, dengan resiko dan tanggung jawab serta tantangan yang dihadapi (Adillah \& Anik, 2015). Oleh karena itu, perlu untuk diberikan perlindungan, pemeliharaan, dan peningkatan kesejahteraannya kepada para peekerja sehingga dapat meningkatkan produktivitas kerja. Suatu perlindungan, pemeliharaan, dan peningkatan kesejahteraan dilaksanakan dalam bentuk jaminan sosial tenaga kerja yang bersifat dasar, dengan mengacu pada usaha bersama, kekeluargaan, dan gotong royong sebagaimana terkandung dalam jiwa dan semangat pancasila dan Undang- Undang Dasar 1945. Jaminan Sosial Tenaga Kerja yang diatur dalam Undang- Undang Nomor 24 Tahun 2011 Tentang Badan Penyelenggaraan Jaminan Sosial Jo. Peraturan Pemerintah Nomor 82 Tahun 2019 tentang perubahan Peraturan Pemerintah Nomor 44 Tahun 2015 Tentang Penyelenggaraan Program Jaminan Kecelakaan Kerja Dan Jaminan Kematian yang dimaksudkan guna memberikan perlindungan bagi tenaga kerja dalam terhadap resiko yang menimpa pada saat kerja. Dalam pelaksanaannya jaminan sosial terhadap tenaga kerja untuk dapat dilaksanakan dengan berhasil baik, maka lebih lanjut diatur dalam Undang- Undag Nomor 13 Tahun 2013 Tentang Ketenagakerjaan dalam Pasal 88 Ayat 1 yang berbunyi Setiap pekerja/buruh berhak memperoleh penghasilan yang memenuhi penghidupan yang layak bagi kemanusiaan dan juga pada Pasal 99 disebutkan bahwa setiap pekerja/buruh dan keluarganya berhak untuk memperoleh jaminan sosial tenaga kerja.

Berdasarkan paparan di atas, penelitian ini bertujuan untuk mengetahui penerapan UndangUndang Nomor 24 Tahun 2011 tentang Badan Penyelenggaraan Jaminan Sosial pada PT. Horiko Abadi, dan mengetahui sanksi hukum terhadap perusahaan dalam hal terjadi pelanggaran terhadap ketentuan dari program jaminan sosial.

\section{METODE PENELITIAN}

Metode penelitian yang dipergunakan dalam penelitian ini yaitu penelitian hukum empiris. Metode penelitian hukum yang menggunakan fakta-fakta empiris yang terjadi di masyarakat yang didapat dari wawancara maupun perilaku nyata yang dilakukan melalui pengatam secara langsung. Penelitian ini dilakukan berlokasi di PT. Horiko Abadi Kabupaten Buleleng di Kecamatan Gerokgak Desa Banyupoh. Sumber data yang dipergunakan dalam penelitian ini yaitu sumber yang diperoleh dari narasumber yang paling utama, dalam hal ini adalah wawancara langsung dengan tenaga kerja di PT. Horiko Abadi. Data dapat diperoleh dengan melalukan wawancara langsung sedangkan data hukum sekunder yang digunakan dari Undang-Undang Nomor 24 Tahun 2011 tentang Badan Penyelenggaraan Jaminan Sosial, Undang-Undang Nomor 40 Tahun 2004 tentang Sistem Jaminan Sosial Nasional dan bahan hukum lain yang berkaitan dengan penelitian ini. 


\section{HASIL DAN PEMBAHASAN}

\section{Penerapan Jaminan Sosial Tenaga Kerja Pada Pt. Horiko Abadi Kabupaten Buleleng}

Perusahaan PT. Horiko Abadi merupakan perusahaan yang bergerak dalam bidang penangkaran kerang mutiara dan budi daya mutiara suatu kegiatan yang ramah lingkungan dan tidak mengambil hasil kekayaan alam melainkan menghasilkan sendiri bibit anakan kerang dengan cara memisahkan induknya di laboratorium yang kemudian dipelihara dilaut untuk dapat menghasilkan mutiara. Perlu kita ketahui terlebih dahulu istilah "pekerja" oleh "kaum" akademisi tidak bisa diterima karena dari segi bahasa istilah "pekerja" mempunyai bahasa yang luas, yaitu "orang yang bekerja" dan orang-orang yang bekerja ini sudah mempunyai istilah-istilah sendiri (Asyhadie \& Kusuma, 2019). Pekerja atau buruh adalah seseorang yang melakukan pekerjaan untuk orang lain dengan diberikannya upah berupa uang atau imbalan dalam bentuk yang lainnya (Pitoyo, 2010). Sebelum dibahas mengenai pelaksanaan jaminan sosial terhadap tenaga kerja pada PT. Horiko Abadi Kabupaten Buleleng, terlebih dahulu akan dijelaskan mengenai hubungan kerja. Sebagaimana telah diketahui bahwa hubungan kerja itu ada setelah timbulnya kontrak kerja atau perjanjian kerja itu sebagai pendahulu (sebelumnya) berlangsungnya suatu ikatan pekerjaan, haruslah diimplementasikan secara baik dalam artian memberikan keadilan baik itu dari pengusaha maupun tenaga kerja. Karena tenaga kerjanya dan pemberi kerja akan terlibat dalam satu lingkup pekerjaan. Kontrak pekerjaan merupakan suatu perjanjian penting, yang isi di dalamnya tentang persetujuan calon pekerja untuk ikut serta dalam perusahaan sebagai karyawan. Sedangkan bagi karyawan, kontrak kerja memiliki fungsi untuk menciptakan rasa aman. Prihal tersebut dikarenakan tertulisnya semua pernyataan berupa hak-hak sebagai karyawan akan terjamin. Jika pihak satu memberikan suatu hak, maka untuk pihak lainnya adalah merupakan suatu kewajiban. Kalau klausul yang terdapat dalam perjanjian kerja tersebut menunjukan kewajiban atau keharusan yang wajib dilaksanakan oleh pihak tenaga kerja, maka kebalikannya bahwa kewajiban pengusaha adalah merupakan hak nya untuk memenuhi kewajiban. Kewajiban yang harus dipenuhi serta hak yang bisa dinikmati bagi mereka yang terikat dalam kontrak kerja, dapat dikatakan sebagai berlawanan antara pekerja dan pemberi kerja.

Selanjutnya akan dibahas tentang pelaksanaan jaminan sosial terhadap tenaga kerja di PT. Horiko Abadi Kabupaten Buleleng. PT. Horiko Abadi, Berdasarkan hasil wawancara dengan Bapak Ketut Sujana, manager personalia PT. Horiko Abadi Kabupaten Buleleng telah mengikut sertakan seluruh tenaga kerja perusahaan sebanyak 35 orang kedalam program BPJS yaitu diantaranya program Jaminan Kecelakaan Kerja, Jaminan Kematian, Jaminan Pemeliharaan Kesehatan, dan Jaminan Hari Tua. Program jaminan sosial pada PT. Horoko Abadi ini telah dilaksanakan pada tahun 2000 baik itu dahulu yang bernama jamsostek dan sekarang menjadi BPJS (Wawancara pada tanggal 10 Februari 2020). Adapun ketentuan jaminan yang diberikan di PT. Horiko Abadi Kabupaten Buleleng meliputi Jaminan Kecelakaan Kerja, Jaminan Kematian, dan Jaminan Pemeliharaan Kesehatan.

\section{Sanksi Hukum bagi Perusahaan Yang tidak Melaksanakan Program Jaminan Sosial Tenaga Kerja}

Untuk adanya jaminan diterapkannya perundang-undangan terkait Ketenagakerjaan, maka perlu sistem pengawasan untuk memberikan pengawasan terhadap terlaksananya Perundangundangan Ketenagakerjaan. Menjadi tugas pemerintah dalam hal ini departemen tenaga kerja untuk melaksanakannya. Adapun tujuan dilakukan nya pengawasan yakni pengawasan terhadap keberlakuan Undang-undang dan Peraturan Perburuhan pada khususnya. Kemudian, mengumpulkan bahan-bahan mengenai ikatan kerja dan kondisi pekerja guna untuk dapat terciptanya Undangundang dan Peraturan Perburuhan. Serta, melaksanakan tugas lainnya yang diberikan kepadanya dengan Undang-undang atau Peraturan lainnya (Kartasapoetra et al., 1992).

Berhubung dengan hal tersebut diatas, maka dalam hal ini pelaksanaan pengawasan oleh Departemen Tenaga Kerja dalam prakteknya dibagi dalam tiga tahap pemeriksaan yaitu: pemeriksaan pertama, dalam pemeriksaan pertama ini melakukan pemeriksaan keseluruhan dalam memeriksa pelaksanaan Undang-undang Ketenagakerjaan. Setelah diadakan pemeriksaan dan apabila ada pelanggaran-pelanggaran yang dilakukan oleh pihak pengusaha, maka pegawai pengawas mengambil langkah-langkah agar ditaati peraturan perundang-undangan sesuai dengan kebijaksanaan 
dan tata cara yang dicantumkan dalam instruksi ataupun edaran, misalnya memberikan pernyataanpernyataan lisan maupun tertulis kepada pengusaha agar mereka memenuhi peraturan-peraturan yang dilanggar dalam batas waktu yang telah dicantumkan. Seterusnya, pemeriksaan ulang, dalam pemeriksaan ulang akan dilihat bahwa apa yang telah disuratkan oleh pegawai pengawas ketenagakerjaan, apakah pengusaha itu sudah memenuhi atau belum syarat yang telah diberikan oleh Pegawai Pengawas dan apabila belum dilaksanakan maka akan diberikan pernyataan kedua dan juga akan diberikan nota pernyataan/nota peringatan kepada pengusaha. Pemeriksaan selanjutnya, apabila pernyataan-pernyataan itu tidak dihiraukan lagi dan pengusaha tetap melanggar peraturanperaturan tersebut maka Pegawai Pengawas tersebut dalam diambil tindakan khusus yaitu dengan memproses verbal atau membuat berita acara pelanggaran yang dilakukan, dan apabila kepolisian memandang berkas sudah memenuhi persyaratan-persyaratan baik formal maupun materiil lalu diteruskan kepada pihak kejaksaan untuk dapat dituntut di depan sidang Pengadilan di wilayah hukum perusahaan itu berada.

Untuk menjamin ditaatinya ketentuan perundang-undangan tentang jaminan sosial terhadap tenaga kerja dalam Peraturan Pemerintah Nomor 44 Tahun 2015 tentang Penyelenggaraan Program Jaminan Kecelakaan Kerja dan Kematian pada Pasal BAB IX memberikan sanksi Administratif. Jenis-jenis sanksi administratif yang dikenal dalam hukum administrasi adalah: Bestuursdwang (paksaan pemerintah); Penankan kembali keputusan (ketetapan) yang menguntungkan (izin, pembayaran, subsidi); Pengenaan denda administratif; Pengenaan uang paksa oleh pemerintah.

Bestuurdwang (paksaan pemerintah) tersebut dapat merupakan tindakan nyata (feitelijke handeling) dari penguasa guna mengakhiri suatu keadaan yang dilarang oleh suatu kaidah hukum administratif atau (bila masih) melakukan apa yang seharusnya ditinggalkan oleh para warga karena bertentangan dengan undang undang. Tindakan Bestuurdwang merupakan tindakan penguasa dengan cara yang amat langsung. Sanksi-sanksi lainnya berperan secara tidak langsung. Penarikan kembali suatu ketetapan yang memberikan keuntungan tidak perlu berdasarkan pada suatu perundangundangan. Prihal ini tidak masuk jika ketetapan itu keberlakuannya untuk jangka waktu yang tidak dapat ditentukan dan dari sifatnya dapat diakhiri atau ditarik kembali (ijin, pembayaran, subsidi). Tidak adanya suatu dasar peraturan perundang-undangan, penarikan kembali itu tidak dapat diadakan, hal ini bertentangan dengan asas hukum.

Pengenaan denda administratif pada dasarnya berupa pengenaan bunga dan denda administratif, yang dikenakan terhadap seseorang atau badan hukum perdata yang tidak melaksanakan kewajiban sebagaimana diatur dalam peraturan perundangan (M.Hadjon et al., 1993). Berkaitan dengan uraian sanksi administratif diatas, maka jenis sanksi administratif yang dapat ditetapkan oleh peraturan perundang-undangan jaminan sosial tenaga kerja adalah: teguran tertulis; denda; dan/atau tidak mendapat pelayanan publik tertentu.

Pengenaan teguran tertulis diatur dalam Peraturan Pemerintah Nomor 88 Tahun 2013 Tentang Sanksi Administratif Pemberi Kerja yang diatur dalam Pasal 6 yang berbunyi bahwa: "(1) Pengenaan sanksi teguran tertulis sebagaimana dimaksud dalam Pasal 5ayat (2) huruf a diberikan paling banyak 2 (dua) kali masing-masing untuk jangka waktu paling lama 10 (sepuluh) hari kerja. (2) Sanksi teguran tertulis sebagaimana dimaksud pada ayat (1) dikenai oleh BPJS.

Sedangkan mengenai sanksi administratif berupa denda diatur dalam Pasal 7 yang berbunyi: (1)terkenanya hukuman denda sebagaimana dimaksud dalam Pasal 5ayat (2) huruf b diberikan untuk jangka waktu paling lama 30 (tiga puluh) hari sejak berakhirnya pengenaan sanksi teguran tertulis kedua berakhir. (2) Sanksi denda sebagaimana dimaksud pada ayat (1) dikenai oleh BPJS. (3) Denda sebagaimana dimaksud pada ayat (2) menjadi pendapatan lain dana jaminan sosial. Selain sanksi administratif yang diberikan terhadap pelanggar terhadap jaminan sosial terhadap tenaga kerja, ada oleh Undang-Undang Nomor 24 Tahun 2011 Tantang Badan Penyelenggaraan Jaminan Sosial, yang dimana diatur dalam ketentuan pidana Pasal 55 yang berbunyi: Pemberi Kerja yang melanggar ketentuan sebagaimana dimaksud dalam Pasal 19 ayat (1) atau ayat (2) dipidana dengan pidana penjara paling lama 8 (delapan) tahun atau pidana denda paling banyak Rp1.000.000.000,00 (satu miliar rupiah). 


\section{SIMPULAN DAN SARAN}

\section{Simpulan}

Berdasarkan uraian dan pembahasan yang telah dipaparkan pada hasil penelitian yang dilakukan maka dapat ditarik beberapa kesimpulan bahwa Pelaksanaan ketentuan jaminan sosial tenaga kerja di PT. Horiko Abadi Kabupaten Buleleng sudah sesuai dengan ketentuan sebagaimana diatur dalam Undang-undang Nomor 24 Tahun 2011 tentang Jaminan Sosial Tenaga Kerja, dimana PT. Horiko Abadi telah mengikutsertakan seluruh tenaga kerja perusahaan sebanyak 35 orang kedalam program BPJS yaitu diantaranya program jaminan kecelakaan kerja, jaminan kematian, jaminan pemeliharaan kesehatan, dan jaminan hari tua. Program ketenagakerjaan pada PT.Horiko Abadi telah dilaksanakan sejak tahun 2000. Dalam hal Sanksi bagi perusahaan yang belum melaksanakan ketentuan dari Undang-undang Nomor 24 Tahun 2011 adalah sanksi administrative yang berupa teguran tertulis, denda, dan tidak mendapatkan pelayanan publik. Serta sanksi pidana yang berupa kurungan penjara 8 (delapan) tahun yang termuat dalam undang-undang Nomor 24 Tahun 2011 sampai perusahaan yang bersangkutan bisa menjalankan ketentuan dari Undang-undang Nomor 24 Tahun 2011 aturan-aturan yang ditetapkan oleh dinas ketenagakerjaan kerjaan dan transmigrasi kabupaten Buleleng, hal ini dapat dilihat dari segi pemberian jaminan sosial kepada tenaga kerjanya.

\section{Saran}

Adapun saran yang dapat diberikan kepada pengusaha untuk lebih meningkatkan kesejahteraan tenaga kerja serta keluarganya atau usaha peningkatan perlindungan tenaga kerja yang dapat memberi jaminan kerja dan sumbangsih terhadap usaha peningkatan disiplin dan produktivitas kerja dan juga kepada kerja pihak departemen tenaga kerja untuk lebih sering memberikan pelatihan ketenagakerjaan sehingga memperoleh tenaga kerja yang berkualitas. Serta lebih sering memberikan penyuluhan hukum dibidang ketenagakerjaan kerjaan agar tenaga kerja dan perusahaan mengetahui hak dan kewajibannya. Dengan demikian akan lebih memberikan kesadaran hukum terhadap tenaga kerja tidak hanya dalam hal keadaan tetapi juga dalam hal alat-alat yang digunakan, sehingga akan menciptakan lingkungan yang aman untuk bekerja.

\section{DAFTAR PUSTAKA}

Adillah, S. U., \& Anik, S. (2015). Kebijakan Jaminan Sosial Tenaga Kerja Sektor Informal Berbasis Keadilan Sosial untuk Meningkatkan Kesejahteraan. Yustisia, 4(3), 558-580.

Ansori, A. H. (2015). Strategi Peningkatan Sumber Daya Manusia dalam Pendidikan Islam. Jurnal Qathrunâ, 2(2), 19-56.

Arfiah, S., \& Setiadi, Y. B. (2012). Pelaksanaan Jaminan Kecelakaan Kerja dalam Jaminan Sosial Tenaga Kerja (Jamsostek) (Studi Kasus pada PT Batik Keris Sukoharjo). Jurnal Pendidikan Ilmu Sosial, 22(1), 10-17.

Asyhadie, H. Z., \& Kusuma, R. (2019). Hukum Ketenagakerjaan Dalam Teori dan Praktik di Indonesia. Pranada Media.

Kartasapoetra, G., Kartasapoetra, A. G., \& Kartasapoetra, R. G. (1992). Hukum Perburuhan di Indonesia Berlandaskan Pancasila. Bima Aksara.

M.Hadjon, P., Martosoeignjo, R. S. S., Basah, S., Manan, B., Marzuki, H. M. L., Berge, J. B. J. M. ten, Buren, P. J. J. Van, \& Stroink, F. A. M. (1993). Pengantar Hukum Administrasi Negara Indonesia. Gajah Mada University.

Manulang, S. H. (2001). Pokok-Pokok Hukum Ketenagakerjaan di Indonesia (3rd ed.). Rineka Cipta.

Maria, S. (2012). Faktor Pendorong Peningkatan Produktifitas Tenaga Kerja Wanita Sektor Industri, Perdagangan dan Jasa di Kalimantan Timur. Forum Ekonomi, 15(2), 55-68.

Pitoyo, W. (2010). Panduan Praktis Hukum Ketenagakerjaan. Visimedia.

Sagir, S. (1998). Masalah Penetapan Upah Minimum Bagi Tenaga Kerja. Forum Ekonomi. 